\title{
Thermal Energy Shifting Using Thermal Energy Storage with Solar Assisted System for Space Cooling Application
}

\section{Authors affiliations:}

1) Mechanical Engineering Department, University of Baghdad, Baghdad-Iraq. abbas ahmed 1985@yahoo.com

2*) Mechanical Engineering Department, University of Baghdad, Baghdad-Iraq. najmosawe@yahoo.com

\section{Paper History:}

Received: $17^{\text {th }}$ Jan. 2020

Revised: $1^{\text {st }}$ Feb. 2020

Accepted: $16^{\text {th }}$ July 2020

\author{
Abbas Ahmed Hasan ${ }^{1}$, Najim Abid Jassim ${ }^{2}$
}

\begin{abstract}
Due to the instability and irregular of national electric power suppled to residence sector in Iraq for long term history, attracted researchers interest to strive for solutions, and associated challenge dry and very hot summer season in Iraq on air conditioning application, A test room full size prototype was constructed in Baghdad, its size $33.5 \mathrm{~m}^{3}$, the room is built from very good thermal insulation Autoclave Aerated Concrete AAC with white panted Concrete roof, test room is exposed to solar radiation during entire day, thermal energy shifted by time using thermal energy storage TES containing PCM, PCM is soft paraffin its phase inversion temperature (29 to 27$)^{\circ} \mathrm{C}$, thermal energy was shifted from night timing by cooling down TES (Discharging PCM) to peak time 11:00 am to 02:00 $\mathrm{pm}$, the testes were carried out over entire summer season April to October, the results showed thermal energy can shift to by any quantity and time based on mass of PCM and enthalpy, electrical energy saved at peak time $52.5 \%$ of total power spent over season $2.7 \mathrm{KW} /$ day, Only $27 \%$ of electric energy utilized to discharge PCM during night, about $43 \%$ of heat lose is sourced from exposed roof, melting and solidification of PCM temperature must be within indoor comfort range 23 to $28{ }^{\circ} \mathrm{C}$ to release or absorb the latent heat $41 \mathrm{~kJ} / \mathrm{kg}$.
\end{abstract}

Keywords: TES, PCM, Energy Shifting, Space Cooling, Solar Assisted System, Charging and Discharging.

$$
\begin{aligned}
& \text { نقل الطاقة الحرارية الزمني باستخدام خزان حراري بمساعدة منظومة شمسية } \\
& \text { للتطبيقات تبريد الفضاءات }
\end{aligned}
$$

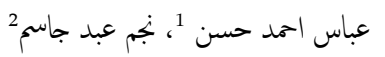

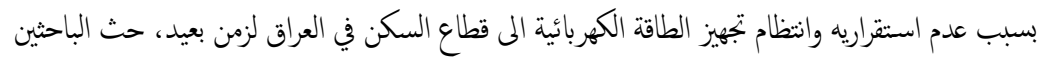

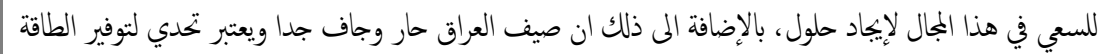

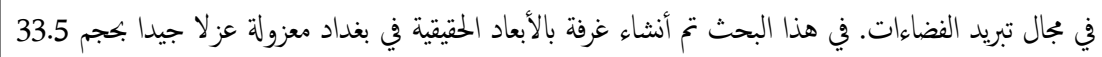

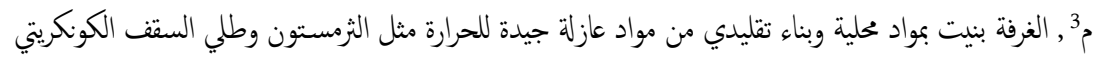

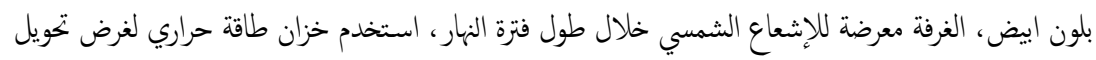

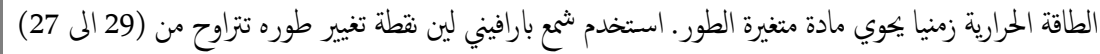

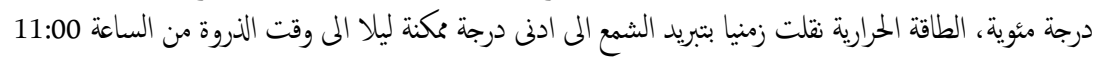

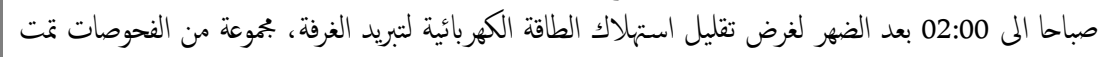

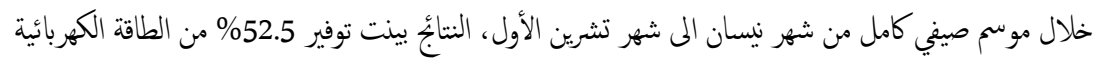

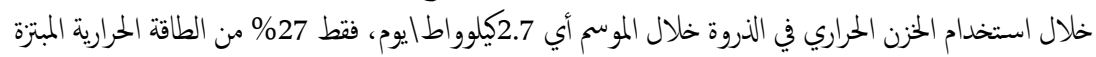

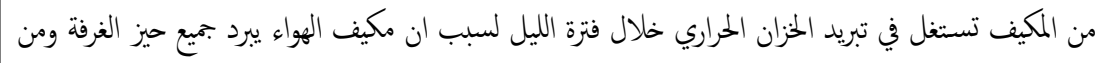

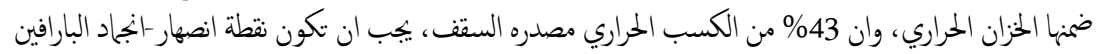
ضمن مجال الراحة للميز الداخلي 23-28 درجة مئوية ليسمح باستثار الحراة الكلمنة للشمع.

NJES is an open access Journal with ISSN 2521-9154 and eISSN 2521-9162

This work is licensed under a Creative Commons Attribution-NonCommercial 4.0 International License 


\section{Nomenclatures}

AAC: Autoclave Aerated Concrete

CLTD: Cooling Load Temperature Difference

PCM: Phase Change Material

TES: Thermal Energy Storage

\section{Problem Definition.}

The major problem is the discontinuity of national electric power supply in Iraq to residence sector, and tremendous electric power consumption with associated cost spent by personals on residence space conditioning during very hot and dry summer, still doesn't satisfy the delivered service.

\section{Problem Solution}

Thermal energy storing and shifting defines as storing the energy from undesired time and use in other timing, a solution was introduced to contribute in solving the national power discontinuity, by utilizing thermal energy storage with assistance of PCM materials, the idea is to absorbs the heat from PCM during availability of electricity A/C unit with relatively less ambient temperature at night to minimize the average temperature of PCM to lowest temperature possible, then shift it to peak time during noon when the ultimate load and demand exist, PCM material is offering the ultimate heat gain or release compare to its mass, because of the latent heat resulted from phase change of liquification or solidification [3].

\section{Objective}

The objective of current research:

1- Shift the thermal energy for space cooling application to absorb the heat from space at peak time when electric national power shutdown, and use electrical solar energy as a secondary power generation system to withstand the operation of air circulation inside the TES and rest of room appliances,

2- Implement local (domestic) row materials in the entire research experiment of room construction, TES fabrication, PCM material ...etc..

\section{Introduction}

Thermal energy shifting in the residence space conditioning application represents a major topic in thermal engineering aspects due to its impact, it simply defines storing the thermal energy at redundancy time by manner and utilize it at desired timing, e.g., discharge the thermal energy during night when there is no demand on electric power and charge it during peak time during the day for space cooling as for heating is vice versa, an electric solar system is equipped to assist and save more power and substitute the electrical supply shortage, as far its impact on environment to minimize the emissions, $27 \%$ of worldwide energy on residence and $17 \% \mathrm{CO}_{2}$ emission [1].

The main focal point of current research is to simulate the case of national electric energy shut down and maintaining the room at comfort temperature range during very hot and dry summer at peak time by utilizing the pre-discharged thermally PCM and absorbed enthalpy of phase inversion with assistance of electrical solar energy on full-size prototype test room.

Many past researcher had their opinion and results, [2] carried out experimental and numerical work on cascaded thermal energy storage with multi PCMs for reason of heat exchange minimization, the process was improved by using metal foam, the comparison was with TES contain single PCM versus cascaded system for different length, air stream velocities, melting temperatures, porosities and other parameters for optimization, results showed the phase change is improved with using metal foam in terms of time and uniform heat propagation, as the caseated system is more TEST with single PCM. The enhancement in melting-solidification time was $33.36 \%$ and $10.15 \%$ respectively, [3] Introduced PCM in building system roof, ground, walls and windows, and utilize its latent heat in TES, the results showed the theoretical work recommend using phase change temperature of PCM within the range of room temperature, use PCM in encapsulation is better due to no leak and low cost, the process was to shift the energy from night to peak day time and save the cost within $1 / 3$ to $1 / 5$, [4] carried out experimental work on room with (PCM-gypsum) integrated with celling including ventilation channels for air flowing. The concept is to cool down the room space at daytime for Warsaw climate by charging part of cooling load into PCM, then discharge PCM by air ventilation at night. The selection of PCM fusion temperature was considered based on thermal comfort and middle temperature oscillation of changing and discharging of PCM. A microencapsulated PCM contain $27 \%$ of composite wall, temperature of (PCM) fusion $22.8{ }^{\circ} \mathrm{C}$, the celling is covered with layer of PCM $6 \mathrm{~cm}$ thick, and has air channels of $3 \times 3 \mathrm{~cm}$ square cross section, and distant $6 \mathrm{~cm}$ from each center, the air channels connected in series for each couple side by side, and each couple connected in parallels with other couples, all couples of channels gathered in manifold 'mounted with ventilation system. Results showed the temperature difference between inlet and outlet air once charging PCM, temperature had dropped approximately from $29.5{ }^{\circ} \mathrm{C}$ to $23.5{ }^{\circ} \mathrm{C}$ for air flows $2 \mathrm{~m} / \mathrm{s}$ over $6 \mathrm{~m}$ full length coupled channel. Transient temperature distribution along the channel showed the PCM melts at the inlet first once charging PCM, meanwhile after 7.5 hrs. PCM still solid at outlet of channel. Measurement over single week period showed part of time were undergoing sensible heat either above or below fusion point of PCM which reduced the overall performance of PCM, [5] Conducted theoretical Numerical study was investigated the thermal energy storage and regenerative for phase change material use. The model was a circular tube passing through PCM media insulated from surrounding; equation of transient heat transfer was solved for unsteady two-dimension conduction heat transfer with heat storage and no heat generation via Finite Difference Method (FDM), (PCM) media is either absorbs of grand heat with 
circular tube carrying water, the study encompasses two types of PCM boundary circular and square. Moreover, a several (PCM) with different fusion temperature $(28,48,64$ and 84$){ }^{\circ} \mathrm{C}$ was simulated for reason of investigation the effect of thermophysical properties of timing of fusion and solidification. Results showed an acceptable convergence with comparing with other experiments; Results showed the circular geometry of outer boundary of PCM causes a PCM to change its phase within shorter time. Thermophysical property is unction of fusion temperature especially Thermal Conductivity, PCM with high Thermal Conductivity reduce timing of phase change, contradicting with Specific Heat, But the amount of latent heat becomes more with longer timing of phase change (Time of response material its phase). Result showed the timing of solidification is less than the timing of fusion (Melting). This is because a thin layer forming has a relatively high thermal conductivity once solidification, [6] Used Energy Plus software to analyses performance of PCM in shopping center buildings, the study was done in five different regions in Iran, they considered climate condition and PCM thickness, type of HVAC, wall specification and Position of PCM layer. The main aim of research is to increase the thermal capacity in building by test various thickness layer of PCM and its position in building (Roof, Floor, Southern Wall .... etc.), and the position of PCM layer whither if its situated inside, outside, or in both sides. Although, they predicted the approximated amount of reduction $\mathrm{CO} 2$ emission which resulted from energy saving by implementing PCM. The PCM was bioPCM instead of ordinary paraffin-based due to the flammability and convergence of thermal characteristics. Results showed the PCM layer situated inside wall is more effective than other cases, moreover, the thickness of PCM gave an exponential relation with heat as results showed the optimization thickness between 4 to $6 \mathrm{~cm}$, The results showed the participation of building construction, the roof or celling was dominated with about $60 \%$ of PCM thermal contribution, while western wall was about $18 \%$ and rest maintained 5$10 \%$. Also for building with poor thermal insulation PCM can play as a thermal insulation due to low thermal conductivity and higher thermal capacity, [7] Studied experimentally and theoretically the energy shifting for space heating and cooling, used two types of PCMs $18^{\circ} \mathrm{C}$ potassium fluoride tetrahydrate $130 \mathrm{~kg}$ and $28^{\circ} \mathrm{C}$ calcium chloride hexahydrate $170 \mathrm{~kg}$ for different phase change melting points, and placed in conical encapsulated, the test and analysis was performed on house situated in Adelaide hourly over entire year, it was able to shift energy during peak time $76 \%$ and $55 \%$ annual heating and cooling load respectively, A rectangular prism TES was used, the $\mathrm{A} / \mathrm{C}$ was discharging and charging the PCM inside TES, [8] The researchers had analyzed performance of PCM storage for heating and cooling process using air based PCM storage with solar energy, the researchers had recommended the melting temperature of PCM during summer was about $29^{\circ} \mathrm{C}$.
Current research will adopt a separate TES installed indoor allows to exchange the heat with PCM by passing forced air through longitudinal circular channels, and the method of discharging will be done by $\mathrm{A} / \mathrm{C}$ at night time when there is no need or demand on power and shift to peak time of the day.

\section{Advantage and Disadvantage of using PCM}

Advantage:

1- Good latent heat per unit mass.

2- Low cost and available.

3- Long durable operation cycle.

4- Simple TES design and construction.

5- Possible to use in heating and cooling applications.

6- Safe in terms of toxic and explosive.

\section{Disadvantage}

1- Initial cost.

2- Possible to have leak.

3- TES occupy space, and if it was built in within building construction it will affect the mechanical properties of building components.

4- PCM expands and shrink in volume noticeably when temperature variation.

5- Unsafe in terms of flammability.

\section{Experimental}

\section{Test Room Prototype}

The test room full-size prototype with dimension $4.7 * 2.5 * 2.85 \mathrm{~m}$ was built in way exposed to solar radiation all day, and walls built from Autoclaved Aerated Concrete blocks AAC with very low thermal conductivity $0.13 \mathrm{~W} / \mathrm{m} . K$, A $0.2 \mathrm{~m}$ wall thickness. $1.8 \mathrm{~m}^{2}$ door and $0.9 \mathrm{~m}^{2}$ window were made from PVC and very good sealed, the roof is made of reinforced concrete slab with iron bar mesh, see Fig. 1.

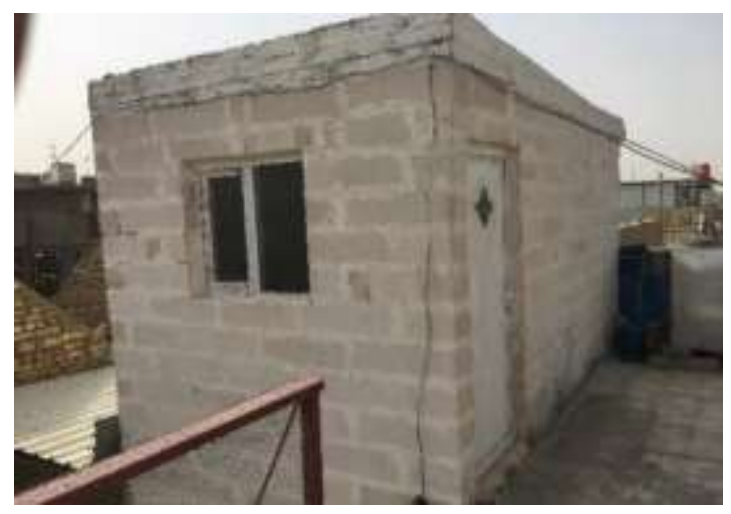

Figure (1): Test room full-size prototype.

\section{Thermal Energy Storage}

A horizontal cylindrical TES contain $175 \mathrm{~kg}$ of soft paraffin as a PCM material placed indoor, it has a five horizontal air passages in matrix shape permits to force the air to flow for thermal exchange reason see Fig. 2. 


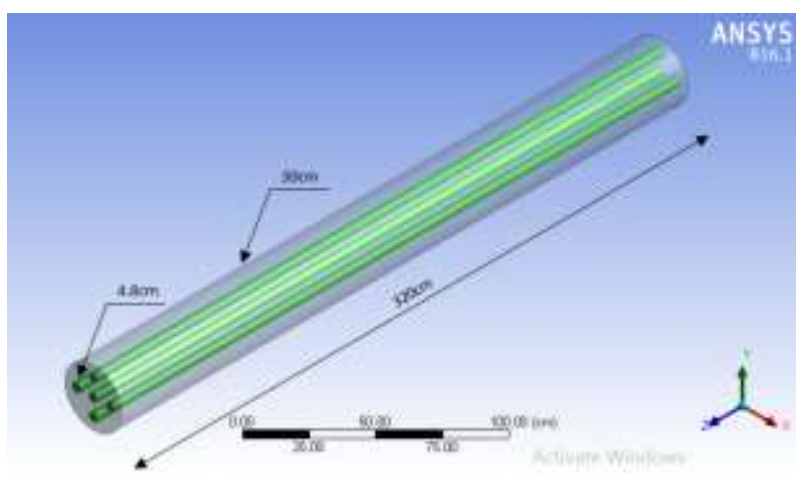

Figure (2): TES sketch and dimension.

TES made of plastic and air channels made from galvanized iron with $1 \mathrm{~mm}$ thickness, TES can handle $7900 \mathrm{~kJ} / 3 \mathrm{hrs}$ of thermal energy, this is a design selection, based on the amount of heat lose during peak time of test room which was pre-estimated using Cooling Load Temperature Difference (CLTD) method [12] during peak time of hottest day in summer 21-July [9], see Fig.3.

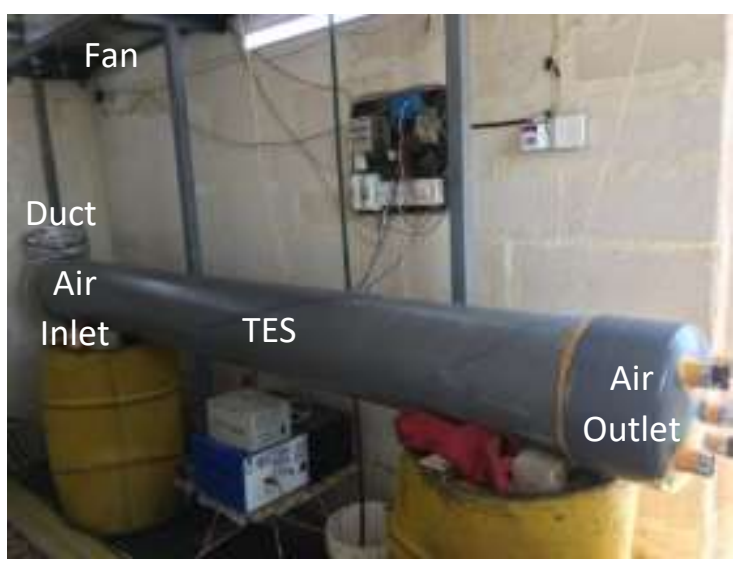

Figure (3): TES Prototype.

\section{PCM (Phase Change Material)}

A soft paraffin is implemented in current research, it was evoked from Daura Refineries with phase inversion temperature $43^{\circ} \mathrm{C}$, the phase inversion point was minimized to range (29 to 27$)^{\circ} \mathrm{C}$ by mixing the liquid paraffin with kerosene $35 \%$ of volume [3] and [10], the major reason is to utilize the enthalpy of PCM at phase inversion temperature must be within space comfortable range [4], as per ASHRI comfort criterial [11] (22 to 27$)^{\circ} \mathrm{C}$, all thermophysical properties required to remeasure post mixing with kerosene, the results showed, Enthalpy of fusion-solidification is $35 \mathrm{~kJ} / \mathrm{kg}, \quad \mathrm{Cp}=1.98 \mathrm{~kJ} / \mathrm{kg} . \mathrm{K}$, Thermal Conductivity $=0.2 \mathrm{~W} / \mathrm{m} . \mathrm{K}$, density $=0.93 \mathrm{~kg} / \mathrm{m}^{3}$ for solid phase and $0.88 \mathrm{~kg} / \mathrm{m}^{3}$ for liquid phase [19] and [20].

\section{Electrical Solar System}

An electrical solar system was adopted to sustain the operation on going when national electric power shutdown, it is representing auxiliary power generation system, it was selected based on required load $240 \mathrm{~W}$ and 3 hr duration, the system consists of couple of PV panels 260W total, controller charger, $210 \mathrm{Amp} / \mathrm{hr}$. battery and invertor capacity 2200W, see Fig. 4.

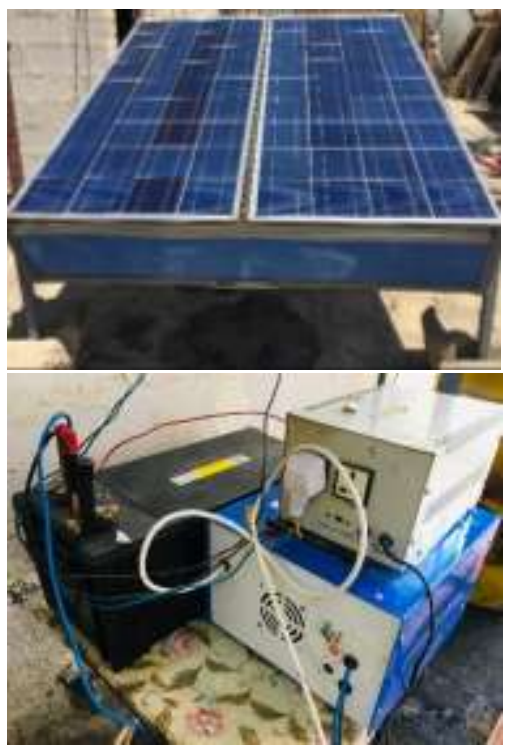

Figure (4): Electric Solar Components.

The selection of A/C capacity 1ton refrigeration based on running software HAP to estimate the suitable $\mathrm{A} / \mathrm{C}$ with concurrent load.

\section{Experimental Tests Procedure}

An essential couple of repeated tests were conducted each month of entire summer season from April to October for comparative reason the tests took in place of tata acquired from instruments from 08:00 till 17:00, the test room is very good insolated and sealed from infiltration. Fig. 5 is showing the test rom section sketch indicating the TES setup and indoor split unit with fan facing the TES that is able to withdraw the cold air from $\mathrm{A} / \mathrm{C}$ indoor unit and blow it to TES air channels (Discharging), and able to circulate the space air when $\mathrm{A} / \mathrm{C}$ shutdown (Charging)

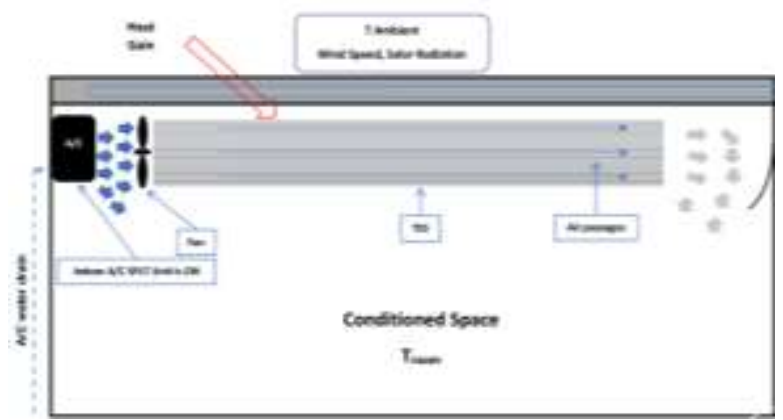

Figure (5): Test Room Sketch.

Test 1: The test room is purely cooled by $\mathrm{A} / \mathrm{C}$ as continues operation from 08:00 till 17:00, simulating the case of national power is continue supply (No shutdown), this represent as a reference of next Test 2 at which the power is off, the acquired data is the total amount of electric power spend, indoor temperature and outdoor ambient parameters (Temperature, Solar 
Radiation and Wind Speed), as well as the associated heat loss from test room components.

Test 2: The test room is subjected to national electric shutdown at peak time, the TES is pre-cooled by A/C indoor unit during night time over $10 \mathrm{hrs}$ to minimize average PCM temperature and becoming in solid state, then the test commence at 08:00 am till 11:00 am the test room is cooled by A/C, from 11:00 am till 14:00 the national electric power offline, and electric solar panel will active to sustain the room lighting and fan to circulate the indoor space air to charge the TES in order to maintain the room within comfort range, then from 14:00 to 17:00 the room is cooled by A/C again.

\section{Theoretical}

The hypotheses of current research to declare and complement to experiment, therefore, the PCM behavior of phase inversion as following; Fig. 6 is showing the phase change with temperature variation presumed constant pressure versus time elapse, however the equation 1 is the governed equation to predict the amount of heat gain or release [13].

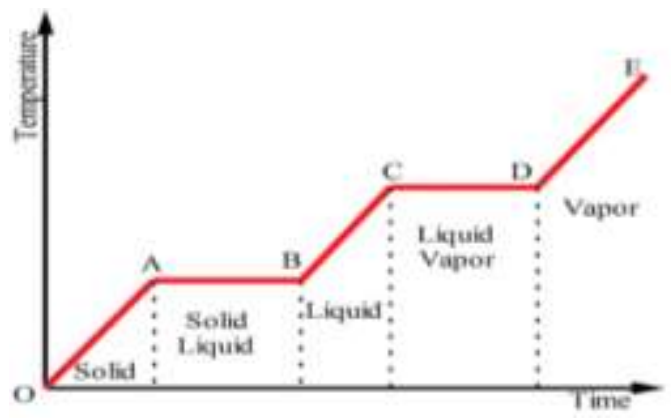

Figure (6): PCM Phase Inversion.

$$
\boldsymbol{Q}=\boldsymbol{m}\left[\boldsymbol{C} \boldsymbol{p}_{\text {liquid }} \Delta \boldsymbol{T}+\boldsymbol{H}+\boldsymbol{C} \boldsymbol{p}_{\text {solid }} \Delta T\right]
$$

TES was analyzed thermally using Ansys software package, the dimension of TES is presented in Fig. 2, the meshing process is by default and the mesh size is about variating and concentrated at interfacing region of two domains (Air convection and PCM conduction) see Fig. 7.

The assumptions were presumed to simplify model, PCM thermal conductivity assumed constant (homogeneous isotropic), constant density, there is no buoyancy effect, temperature diffuses in three cylindrical dimensions with time dependent.

The boundary conditions set to solve the energy equation of PCM domain and to solve (continuity, momentum and energy equations) of air convection domain, assumed that the air enters the pipe with certain velocity in direction $-z$ axis and certain temperature, and exits to open area has no back pressure applied, TES is thermally insulated from ends and body, thermal exchange between domains is based on direct contact with thin material $0.5 \mathrm{~mm}$ thickness galvanized iron.
The governing equation of unsteady state threedimension cylindrical coordinate is equation 2: [14]. $\frac{1}{r} \frac{\partial}{\partial r}\left(r \cdot k \frac{\partial T}{\partial r}\right)+\frac{1}{r^{2}} \frac{\partial}{\partial \phi}\left(k \frac{\partial T}{\partial \phi}\right)+\frac{\partial}{\partial z}\left(k \frac{\partial T}{\partial z}\right)+\dot{e}_{g e n}=\rho c \frac{\partial T}{\partial t}$

Assumed the PCM is constant K, TES is insulated from boundary, and forced convection is taking in place in air passages with known inlet temperature and velocity, the air will exchange the heat from/to PCM, the outlet air is opened to zero pressure aria, Fig. 7 is the TES meshing model.
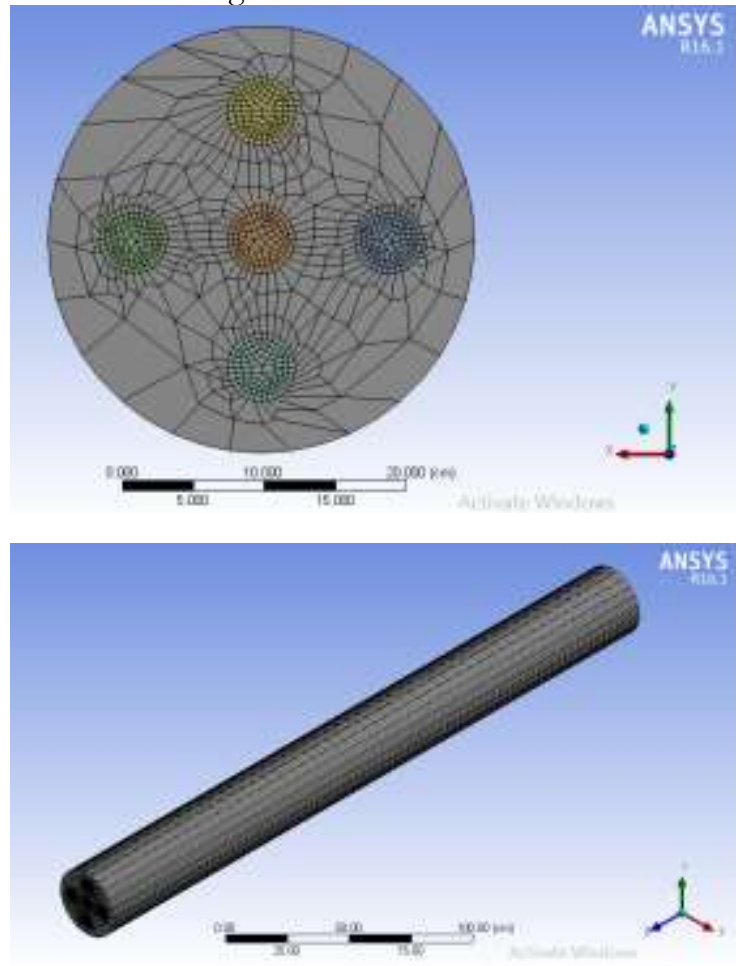

Figure (7): Ansys Model Mesh.

Heat exchange by air forced convection from/to PCM can be estimated by following equation based on flowing typr weither turbulent or laminar for developing flow [16]:

For Laminar flow

$$
\begin{aligned}
& \overline{N u}=\frac{1}{2 z^{+}} \ln \left(\frac{1}{\theta_{b}}\right) \\
& Z^{+}=\frac{L / R i}{R e P r} \text { and } \theta_{b} \text { from table }
\end{aligned}
$$

For Turbulent flow

$$
\overline{N u}=0.036 \operatorname{Re}^{0.8} \operatorname{Pr}^{1 / 3}\left(\frac{R i}{L}\right)^{0.055}
$$

Moreover it can be evaluated by:

$$
Q=\dot{m} \cdot C(\text { Tout }- \text { Tin })_{a i r}
$$

The national electric energy consumption was directly measured by counter W.hr, the amount of heat gain is estimated by Cooling Load Temperature Difference (CLTD) [9] the effect of ambient temperature and solar temperature. By applying energy balance on test room. 


$$
\sum Q_{\text {in }}+\sum Q_{\text {gen }}=\sum Q_{\text {out }}+\sum Q_{\text {store }}
$$

$\sum Q_{i n}$ : is Total thermal energy entering the room space $\mathrm{KW}$.

$$
\begin{aligned}
& \sum Q_{\text {in }}=Q_{\text {wall }}+Q_{\text {roof }}+Q_{\text {window }}+Q_{\text {door }}+ \\
& Q_{\text {infilitration }}+Q_{\text {ground }}
\end{aligned}
$$

The general equation of components facing solar radiation is:

$$
\begin{aligned}
& Q=U . A . C L T D \\
& Q_{g}=U . A .\left(T_{\text {uncond.space }}-T_{\text {roon }}\right)
\end{aligned}
$$

$Q_{\text {infilitration }}=1.22 \cdot \dot{v} \cdot 1.005\left(T_{\text {amb }}-T_{\text {roon }}\right) . .(11)$ $\sum Q_{g e n}$ : Is thermal energy generated inside the control volume. Dissipated heat from lights and fan KW [15]. $\sum Q_{\text {out }}$ : Energy been extracted from control volume.

\section{Validation of Numerical with Experiments}

Intensive experiment was conducted to obtain a result, to know the behavior of flow and PCM melting and solidification, a numerical modeling was run by Ansys Fluent, the unsteady state numerical work with initial condition and boundary conditions were compared to with experimental at different time period, while charging and discharging, e.g., at time $=0$ $\mathrm{sec}$, the air inlet velocity and temperature is known, the air outlet temperature can be measures, as well as the average PCM temperature, after certain time PCM temperature will change in accordance with air outlet temperature, numerical results compared with experimental presuming same initial and boundary condition of certain case and same time interval, and compare the results, average PCM temperature and air outlet temperature were very close 1 to $1.5 \pm{ }^{\circ} \mathrm{C}$.

\section{Error Analysis and Accuracy}

The temperature measurement was calibrated with manual thermometers, and found that the expected error doesn't exceed $0.5 \pm{ }^{\circ} \mathrm{C}$, e.g., the heat gain for certain day $14200 \mathrm{~kJ} / 10 \mathrm{hrs}$, considering the temperature difference round of error of heat gain will be $13750 \mathrm{~kJ} / 10 \mathrm{hrs}$, the error will be $3.1 \%$ which is acceptable. For power measurement, the manual reading taken from counter is compared with instant measured current multiplied by voltage and reading showed very close values.

\section{Results and discussions}

Extensive experimental results showed that the average temperature behavior trend of PCM when discharging and charging is shaping in Fig. 8, the reference temperature is $25^{\circ} \mathrm{C}$ of indoor temperature, the PCM is discharged to minimized its average temperature about $9^{\circ} \mathrm{C}$, at $07: 45 \mathrm{am}$ it is kept stable about $20^{\circ} \mathrm{C}$ small rise in PCM temperature at 11:00 am due to heat transfer from room space to TES, from 11:00 am till 14:00 a remarkable increase in PCM temperature due to thermal exchanging with environment about $9^{\circ} \mathrm{C}$.

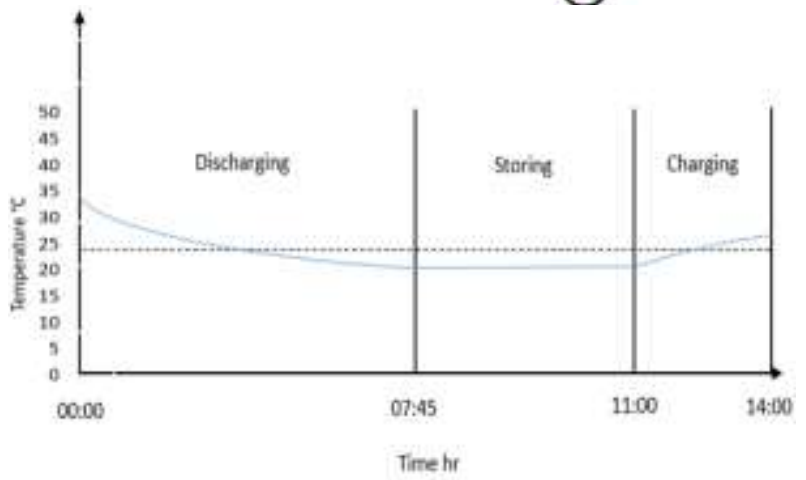

Figure (8): PCM Temperature vs. time.

The electrical energy taken by A/C to perform the entire testes (Test 1 and Test 2 ) presented earlier Fig. 9 will describe it:

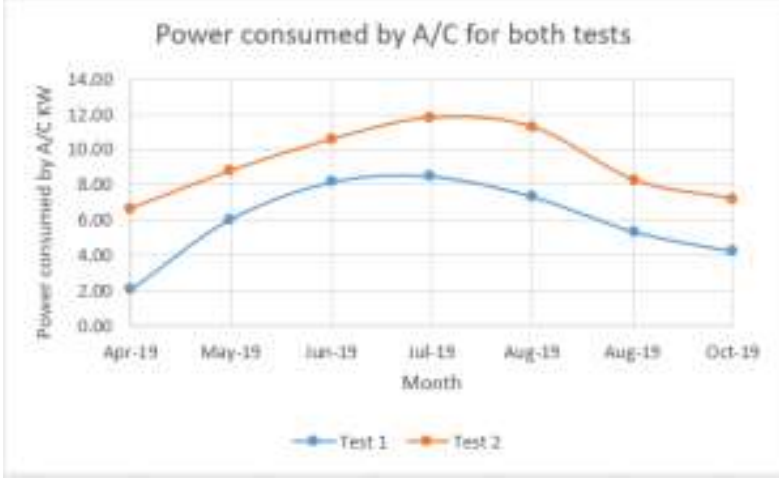

Figure (9): Power consumed comparison.

Fig. 9 showing the experiment results that Test 2 consumes power more than Test 1 , the reson is the A/C working hours of test 2 is more than Test 1 to discharge the PCM. The power spent on A/C to discharge PCM during the night with duration of operation is discribed in Fig. 10, overall the duration of discharging took about $10 \mathrm{hr}$, it's indicating the A/C consumes more power during hotest months in summer season for the reason of influnce heat gain due to significant temperature difference between the indoor and outdoor, moreover the $\mathrm{A} / \mathrm{C}$ coefficient of performance is affected and decent when operated in very hot outdoor temperature [17] and [18],

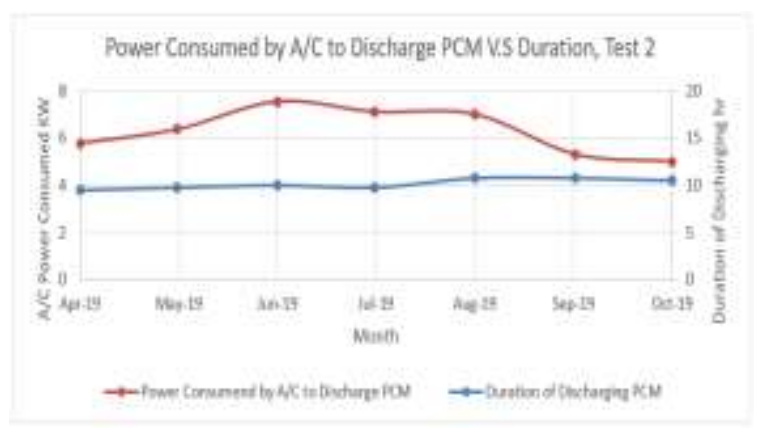

Figure (10): Power consumed by $\mathrm{A} / \mathrm{C}$ to discharge TES. 
Fig. 11 is showing the effect of heat gain versus temperature of PCM during only discharging period which is 3 hrs of peack time, it is showing the PCM temperature is increasing with hotest monthes in summer, whilest Fig. 12 presnting a selective day variation of power on $\mathrm{A} / \mathrm{C}$ vesus the heat gain.

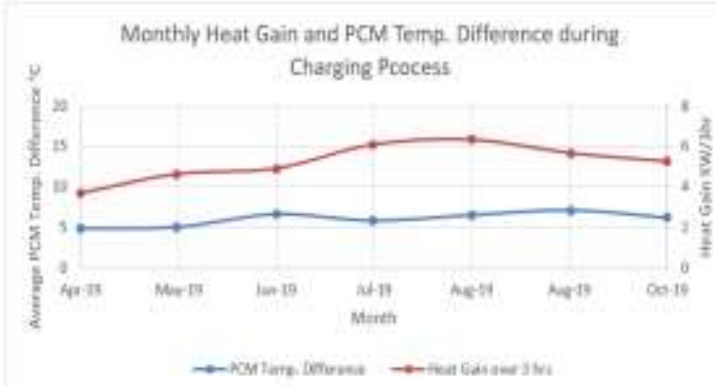

Figure (11): Heat gain vs. PCM Temp. Discharging.

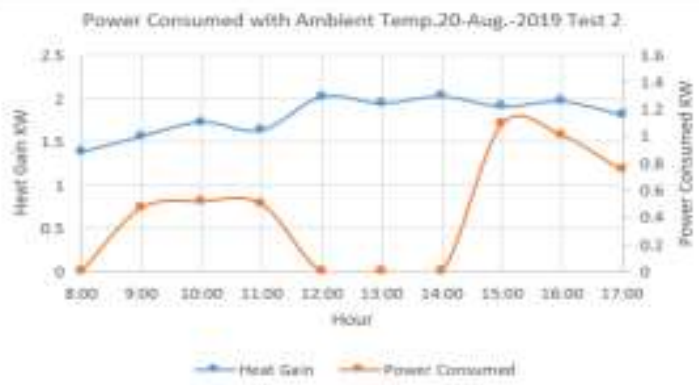

Figure (12): Heat gain vs. Powerconsumed.

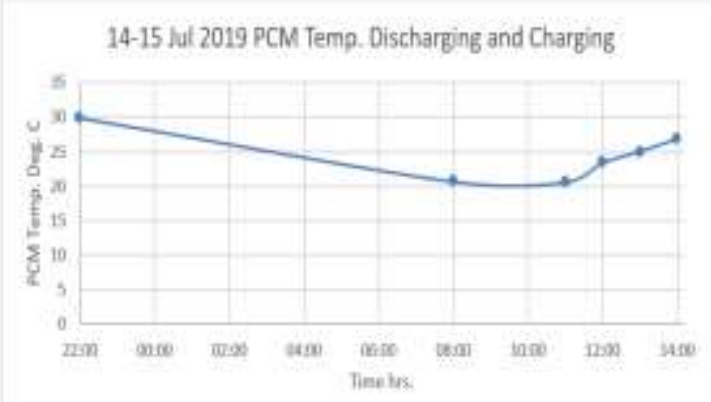

Figure (13): Figure (5.20.A): PCM Temp. during discharging and charging.

Fig. 13 is interpretating the PCM temperature periodinf history of selective day, starting from discharging during night ahead till charging during noon, including temperature difference, PCM cool down about $8.5^{\circ} \mathrm{C}$ during $10 \mathrm{hrs}$, resulting phase transion from liquid into solid, and during charging about $6.5^{\circ} \mathrm{C}$ of temperature will increase resulting partial liquid-solid phase.

Theoretical simulation results by Ansys fluent solved the governing equation 2 numirically with certain initial and boundary conditions, the results showed the temperature distribution in air convection domain as in fig. 14 and 15 , the velocity of air is $5.2 \mathrm{~m} / \mathrm{s}$ for the inlet temperature 18 and 26 of cases discharging and charging respectively, Fig. 16 is showing the pressure drope cross the air axis in $\mathrm{z}$ direction (flow direction), and Fig. 17 is showing the $\mathrm{Nu}$ (Nusselt No.) in air domain at where the forced convection on going, Note the inlet is reveres from right to left.

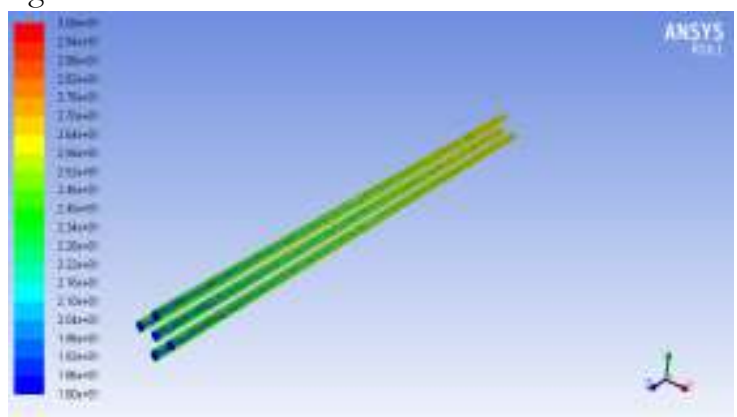

Figure (14): Air temp. contours while discharging.

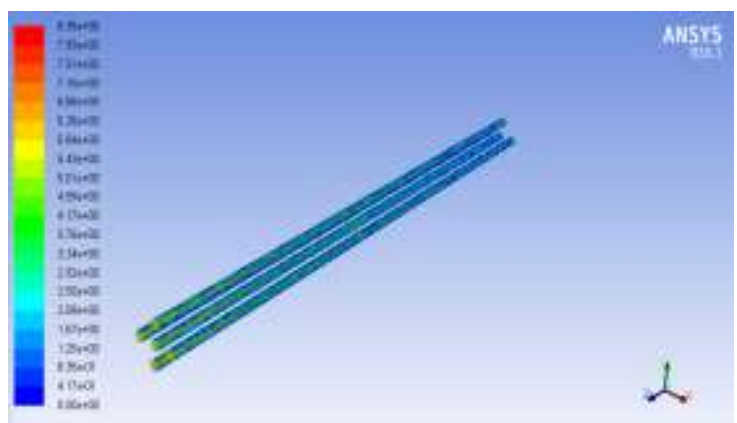

Figure (15): Air temp. contours while charging.

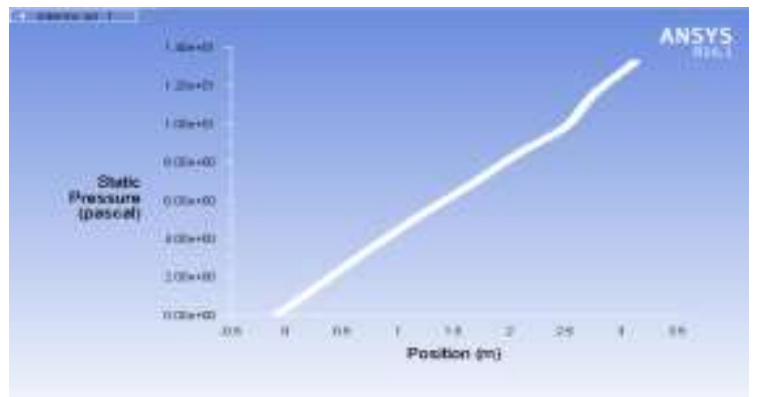

Figure (16): Air flow pressure drop cross z-axix.

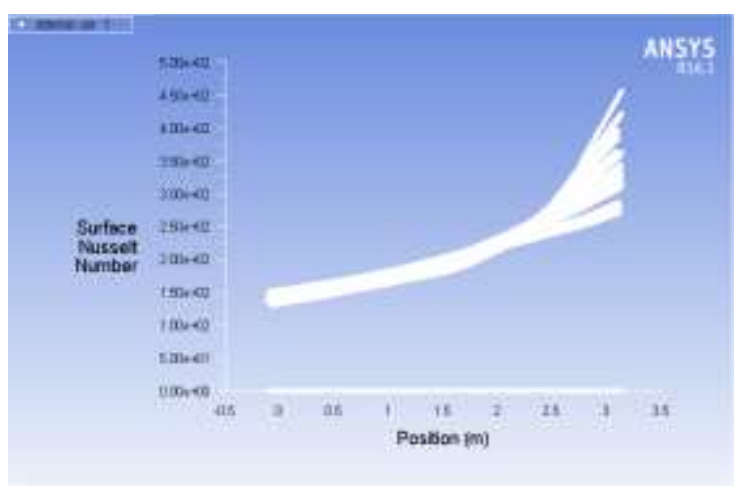

Figure (17): Nu No. in forced convection z-axix.

The PCM doamins temperature contouers are indicated in Fig. 18 and 19 for charging and discharging after $900 \mathrm{sec}$, as it is seen the ultimate temperature variation occures where is the temperture is sourced or sunk (air chanels). 


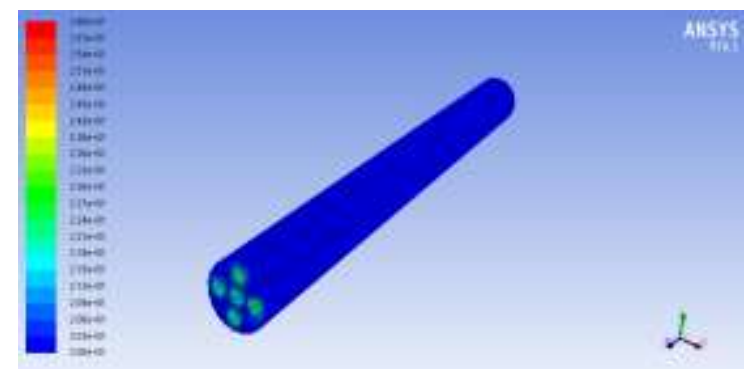

Figure (18): PCM Temp contours while charging.

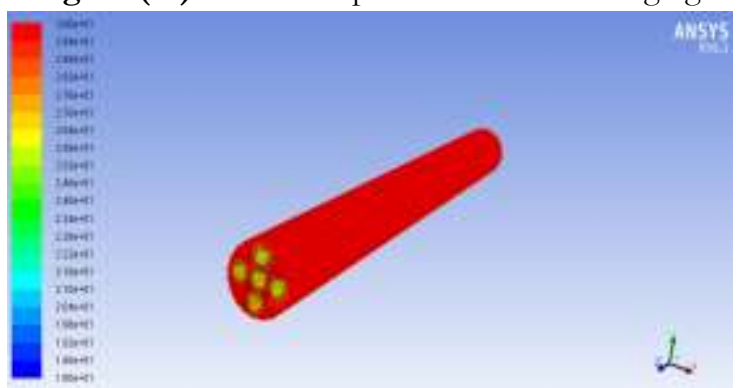

Figure (19): PCM Temp contours while discharging.

The flow behavior is presented in Figs. (20 and 21), it is showing different air flow velocities at the inlet versus Turbulent Reynolds No. and its reflection of heat transfer by Nusselt No. as a direct relation, the experiment was held on $3 \mathrm{~m} / \mathrm{s}$ and $5.9 \mathrm{~m} / \mathrm{s}$ and excluded the rest because considering the electrical energy consumed by fan and high sound resulted from flow turbulence, which is practically not applicable to obtain comfort and silence operation.

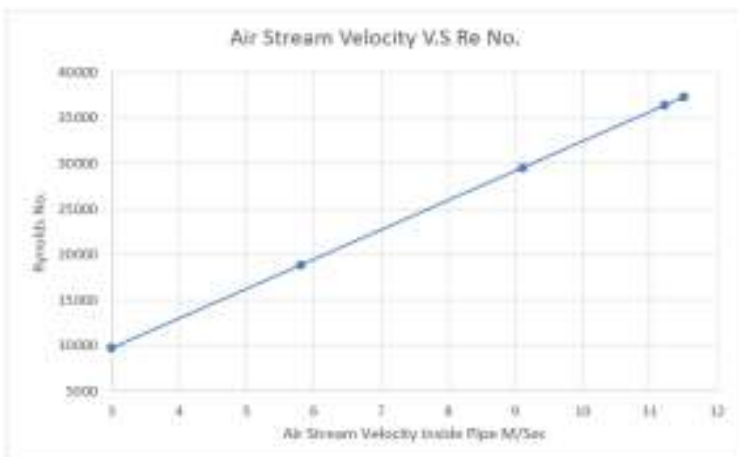

Figure (20): Air stream velocity vs. Reynolds No.

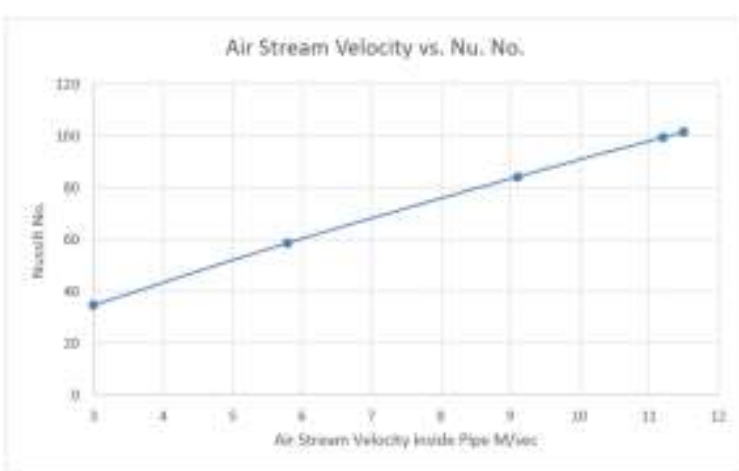

Figure (21): Air stream temp. vs. Nusselt No.
HEAT GAIN FRACTION THROUGH TEST ROOM CONSTRUCTION COMPONENTS

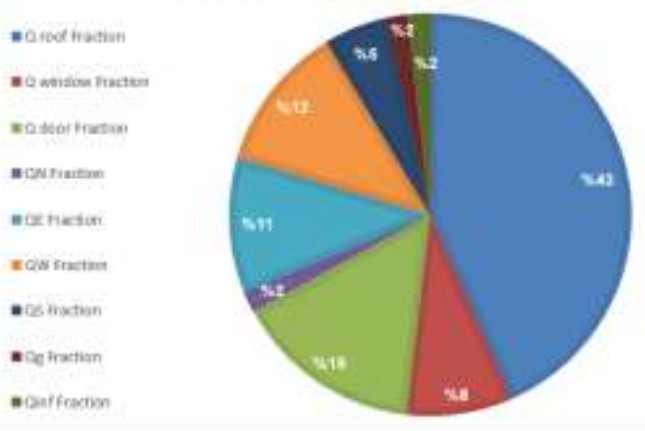

Figure (22): Heat Gain from room construction components.

\section{Conclusion}

It can deduce the following from experiment and theoretical simulation:

1. PCM material used in application of residence cooling and it can be used to store the heat for heating, its phase conversion temperature must be within comfort temperature range 22 to $27^{\circ} \mathrm{C}$.

2. electrical energy saved at peak time $52.5 \%$ of total power spent over season $2.7 \mathrm{KW} /$ day.

3. Electrical energy spends on $\mathrm{A} / \mathrm{C}$ to discharge PCM and shift the energy to peak time is more than the test of full operation without energy shifting within $64 \%$ increasing.

4. Only $27 \%$ of energy spend on discharging process alone by $\mathrm{A} / \mathrm{C}$ is going to discharge the PCM heat casing minimize its temperature, because the $\mathrm{A} / \mathrm{C}$ must cool down the entire space during night as well as the effect of TES effectiveness.

5. It is possible to shift thermal energy to any time and any quantity, considering the energy spend on discharging (cooling down PCM) and the massive amount of PCM as well as the type of PCM (latent heat).

6. TES maintain the room temperature within comfort temperature range during peak time over 2.5 hours, the las half hour there is a significant temperature increase. Especially during very warm summer days.

7. Air velocity inside air passages or Reynolds No. is directly proportional to amount of heat transfer and Nusselt No. as it is influencing the charging/discharging timing of PCM, increase Reynolds No. will increase heat transfer and minimize charging/discharging timing.

8. Solar energy is powerful method to save energy, it is available energy if the sun rise is there.

9. The major fraction of heat gain is sourced from ambient exposure roof about 43\% see Fig. (22). 


\section{References}

[1] Nejat, Payam, Jomehzadeh, Fatemeh, Taheri Mohammad, Gohari, Majid Muhd, "A global review of energy consumption, $\mathrm{CO} 2$ emissions and policy in the residential sector (with an overview of the top ten CO2 emitting countries)", Renewable and Sustainable Energy Reviews, Vol. 43, P.p 843-862, 2015.

[2] Hasan Hiba and Hussain Ihsan, "Thermal Performance Enhancement of Phase Change Materials (PCMs) by Using Cascade Thermal Energy Storage (CTES) System with Metal Foam", Ph.D. Thesis, University of Baghdad, 2018.

[3] Zhang Y., Zhou G., Lin K., Zhang Q., Di H., "Application of latent heat thermal energy storage in buildings: State-of-the-art and outlook", Tsinghua University, Beijing, Elsevier Ltd., 2006.

[4] Jaworski Maciej, Jędrzejuk Hanna., Laskowski Rafał., "Experimental Study of Heat Storage Unit Made of PCM-gypsum Composite Integrated with the Ventilation System of the Building", Vilnius Gediminas Technical University, Lithuania, Environmental Engineering, 10th International Conference, (2017).

[5] Taha A. Q. and Joudi K. A., "Simulation of Heat Storage and Heat Regeneration in PCM", M.Sc. Thesis, University of Baghdad, 2010.

[6] Sajadi, Behrang. and Baniassadi, Amir, "On the effect of using phase change materials in energy consumption and $\mathrm{CO} 2$ emission in buildings in Iran: a climatic and parametric study", Energy Equipment and Systems, energyequipsys, Vol. 3, No.2, P.p. 73-81, 2015.

[7] Vakilaltojjar Saied, "Phase Change Thermal Storage System For Space Heating and Cooling", Ph.D. Thesis, University of South Australia, Sustainable Energy Centre, 2000.

[8] Khalil M. H., Sheble S.S., Morsy M. S., Fakhry S., "Thermal Performance of Exposed Composed Roofs in Very Hot Dry Desert Region in Egypt (Toshky)", Housing \& Building National Research Center (HBRC), Cairo, Egypt, 2010.

[9] Al-Judi Khalid A. "Fundamental Engineering of Air Conditioning and Cooling", Text Book, 2nd edition, Al-Basra University, 1991.

[10] Akeiber Hussien, Wahid Mazlan, Taha Mahdi, Jassim Nasir and Obeid Mohammed, "Production Application of Paraffin Waxes Refining Process in Iraq and used as Phase Change Materials", International Journal of Advanced Research, Volume 4, Issue (1): 96- 100, 2016.

[11] ASHRE Fundamentals, (SI Edition), 2005.

[12] Stoecker W. F. and Jones J. W., "Refrigeration and Air-Conditioning", Text Book, 2nd Edition, McGrawHill, Inc., (1982).

[13] Kunal G., Shubham S., Shubham G., Shivade K., "A Review on Thermal Energy Storage Using Phase Change Material", ijates, Vol. No. 4, Issue No. 03. 2016.

[14] Arpaci V. S.," Conduction Heat Transfer", Text Book.

[15] Y. Ali Cengel, "Heat Transfer: A Practical Approach"., Textbook, July. (2002).

[16] Bejan Adrian," Convection Heat Transfer",
TextBook, Fourth Edition, 2013.

[17] Farhan Ammar and Joudi Khalid, "Solar assisted desiccant system for air-conditioning a greenhouse in Baghdad", Ph.D. Dissertation, University of Baghdad, 2013.

[18] Wandra Rahul, Hussain Taliv, Roy Gourav and Thukral Rahul, "Experimental Study of Improving the COP of VCRS system by using Single and Double Cellulose pad in Cooling Tower", IOSR Journal of Mechanical and Civil Engineering, PP 64-68, 2014.

[19] Benjamin Young, Alexander Thiele, Amanda Fujii, Gaurav Sant, Laurent Pilon, "Thermophysical Properties of PCM", UCLA Henry Samueli School of Engineering and Applied Sciences, 2013.

[20] Hammendy Ban, Albaldawi Rafa, Shyaa Aseel, "Experimental and Numerical Model of a Phase Change Material (PCM) with Thermal Conductivity Enhancers", M.Sc. Thesis, Mechanical Engineering Department, Al-Mustansiriyah University, 2012. 